\title{
Minimal change disease following vaccination for SARS-CoV-2
}

\author{
Nicoletta Mancianti ${ }^{1} \cdot$ Andrea Guarnieri $^{1} \cdot$ Sergio Tripodi $^{2} \cdot$ Domenica Paola Salvo $^{1} \cdot$ Guido Garosi $^{1}$
}

Received: 11 May 2021 / Accepted: 9 June 2021 / Published online: 18 June 2021

(c) Italian Society of Nephrology 2021

Keywords BioNTech/Pfizer vaccine $\cdot$ COVID-19 $\cdot$ Glomerular disease $\cdot$ Minimal change disease $\cdot$ SARS-CoV-2 vaccine

\section{The Case}

A 39-year-old Caucasian male with a history of biopsyproven minimal change disease with nephrotic syndrome, at one year of age, without recurrences after 6 months of steroid treatment, had been of regular follow-up for 37 years. Three days after administration of the first dose of the BioNTech/Pfizer SARS-CoV-2 vaccine (BNT162b1 ${ }^{\circledR}$ ) he developed weakness, fatigue, and lower limb edema. On the eighth day after vaccination, he was admitted to our Nephrology Unit with acute kidney injury (AKI) (serum creatinine $1.8 \mathrm{mg} / \mathrm{dl}$ vs baseline $0.9 \mathrm{mg} / \mathrm{dl}$, creatinine clearance $44 \mathrm{ml} / \mathrm{min}$ ) and full-blown nephrotic syndrome (proteinuria $8 \mathrm{~g} / 24 \mathrm{~h}$, unremarkable urine sediment, albuminemia $2.7 \mathrm{~g} / \mathrm{dl}$, total cholesterol $470 \mathrm{mg} / \mathrm{dl}$, generalized peripheral edema). Diuresis was unaffected. Common causes of renal failure (nephrotoxic agents, dehydration, autoimmune and infectious diseases) were excluded. No infectious event or other relevant condition occurred in the weeks prior to the onset of nephrotic syndrome, except for the administration of the vaccine. Abdominal ultrasonography was unremarkable. A renal biopsy was diagnostic for minimal change disease (MCD) (Fig. 1). Oral prednisone (1 mg/kg for 4 weeks) was prescribed. The clinical picture rapidly improved with complete regression of proteinuria. Renal function was normal at the follow-up visit at the end of therapy. The steroid was discontinued after standard tapering. To date, the patient has not received the second dose of the vaccine. An interesting remark: he had been vaccinated against seasonal

Andrea Guarnieri

andrea.guarnieri@ao-siena.toscana.it

1 Department of Emergency-Urgency and Transplantation, Nephrology, Dialysis and Transplantation Unit, University Hospital of Siena, Siena, Italy

2 Department of Oncology, Pathology Unit, University Hospital of Siena, Siena, Italy influenza (split inactivated vaccine) 6 months earlier without side effects.

\section{Lessons for the clinical nephrologist}

Messenger RNA (mRNA) vaccines against coronavirus disease 2019 (COVID-19) have emerged with exceptional speed, as a flagship of the innovation process in medicine [1]. As mRNA is a non-infectious, non-integrating platform, there is no risk of insertion-induced mutagenesis or infection [2]. Target immunogenic epitopes can be easily inserted and removed to adapt to a mutated or newly emerged virus strain quickly. Compared to traditional vaccines, they are expected to produce a higher antibody response and a stronger CD8+T- and CD4+ T-cell response, including higher production of chemokines and cytokines [1,3]. A consequent dysregulation of permeability factors could result in relapsing glomerulonephritis. In this sense, a crosslink between the mRNA vaccine and relapsing glomerulonephritis should be considered [4].

To the best of our knowledge, very rare cases of biopsyproven relapsing glomerulonephritis following COVID19 vaccination have been previously reported including a paper by Rovin et al. who described two cases of known IgA nephropathy showing gross hematuria following the second dose of the Moderna vaccine [5].

The interest in our case is that it depicts biopsy-proven relapsing glomerulonephritis (namely MCD) arising after the first dose of BNT162b1 ${ }^{\circledR}$. MCD had been silent for 37 years and was once again fully responsive to short-term steroid therapy, despite a severe onset with AKI and fullblown nephrotic syndrome.

Further data are emerging. Labedev and colleagues [6] described another case of MCD after BNT162b $1{ }^{\circledR}$ first dose. In this case, the patient had never had any previous episodes of glomerulopathy. As in our case, the patient developed 

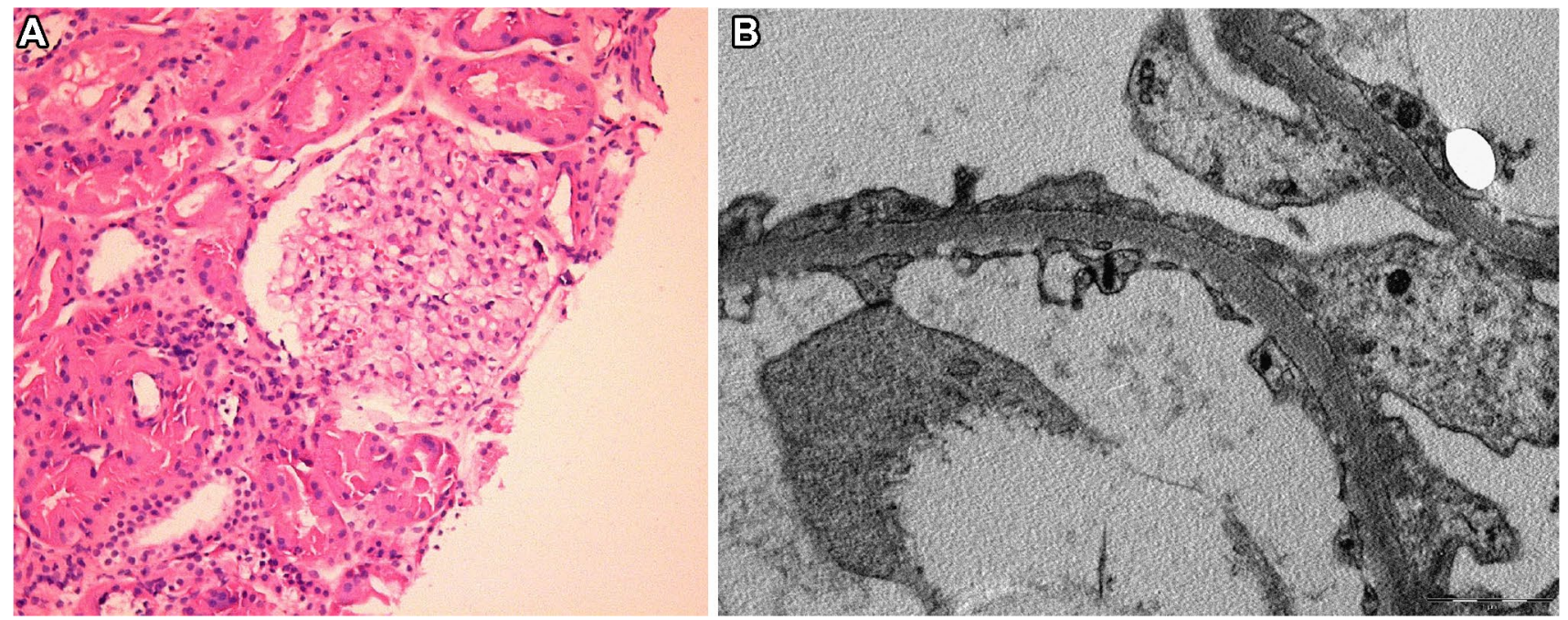

Fig. 1 Minimal change disease on the renal biopsy. a Light microscopy, $\mathbf{b}$ transmission electron microscopy $(\times 800)$ : diffuse effacement of foot processes. Immunofluorescence was negative

AKI and nephrotic syndrome a few days after the first dose of the BioNTech/Pfizer SARS-CoV-2 vaccine. The close temporal association suggests that the mRNA vaccine may have been the trigger for T-cell mediated podocytopathy. The prompt performance of a renal biopsy and the start of standard steroid therapy led to complete remission of AKI and nephrotic syndrome, as in our case.

Although the pathogenesis of MCD remains unclear, the immunological dysregulation of $\mathrm{T}$ lymphocytes appears to be decisive $[7,8]$. The therapeutic efficacy of steroidbased immunosuppression strongly reinforces these findings. Clinical studies have shown an imbalance in T-cell subpopulations during the active phase of minimal change disease, with a prevalence of circulating CD8+ suppressor $\mathrm{T}$-cells, aggravating the nephrotic syndrome in mouse models through cytokine-induced damage (Th2; IL4, IL5, IL9, IL10, and IL13) [9].

The global use of mRNA vaccines underlines the importance of collecting information on their potential role of triggers of glomerular diseases. In patients with glomerular diseases, and above all, in patients with onset or relapse of glomerular diseases it is probably not safe to administer second doses of mRNA vaccine or future boosters. Special attention in the follow-up post-vaccine anti COVID-19 of patients with glomerular diseases is highly needed.

\section{Declarations}

Conflict of interest The authors have no conflict of interest to declare.

Ethical Statement The patient authorized the publication of the clinical case according to the ethical statement.

\section{References}

1. Pardi N, Hogan MJ, Porter FW, Weissman D (2018) mRNA vaccines - a new era in vaccinology. Nat Rev Drug Discov 17(4):261279. https://doi.org/10.1038/nrd.2017.243

2. Wang F, Kream RM, Stefano GB (2020) An evidence based perspective on mRNA-SARS-CoV-2 vaccine development. Med Sci Monit 26:e924700. https://doi.org/10.12659/MSM.924700

3. Sahin U, Muik A, Derhovanessian E et al (2020) COVID19 vaccine BNT162b1 elicits human antibody and T. Nature 586(7830):594-599. https://doi.org/10.1038/s41586-020-2814-7

4. Imig JD, Ryan MJ (2013) Immune and inflammatory role in renal disease. Compr Physiol 3(2):957-976. https://doi.org/10.1002/ cphy.c120028

5. Negrea L, Rovin BH (2021) Gross hematuria following vaccination for SARS-CoV2 in two patients with IgA nephropathy. Kidney Int. https://doi.org/10.1016/j.kint.2021.03.002

6. Lebedev L, Sapojnikov M, Wechsler A et al (2021) Minimal change disease following the Pfizer-BioNTech COVID-19 vaccine. Am J Kidney Dis S0272-6386(21):00509-00516. https:// doi.org/10.1053/j.ajkd.2021.03.010

7. Mathieson PW (2003) Immune dysregulation in minimal change nephropathy. Nephrol Dial Transplant 18(Suppl 6):vi26-vi29. https://doi.org/10.1093/ndt/gfg1066

8. Hashimura Y, Nozu K, Kanegane H et al (2009) Minimal change nephrotic syndrome associated with immune dysregulation, polyendocrinopathy, enteropathy, X-linked syndrome. Pediatr Nephrol 24(6):1181-1186. https://doi.org/10.1007/s00467-009-1119-8

9. Le Berre L, Hervé C, Buzelin F, Usal C, Soulillou JP, Dantal J (2005) Renal macrophage activation and Th2 polarization precedes the development of nephrotic syndrome in Buffalo/Mna rats. Kidney Int 68(5):2079-2090. https://doi.org/10.1111/j.1523-1755. 2005.00664.x

Publisher's Note Springer Nature remains neutral with regard to jurisdictional claims in published maps and institutional affiliations. 